\title{
ORdENAÇÃo DE CONSTITUINTES EM CONSTRUÇÕES \\ CATEGORIAL, TÉTICA E APRESENTATIVA
}

\section{(Constituent ordering in categorical, thetic and presentative constructions)}

\author{
Erotilde Goreti Pezatti ${ }^{1}$ \\ (Universidade Estadual Paulista/São José do Rio Preto)
}

\begin{abstract}
The ordering of clausal constituents in Portuguese varieties is treated here considering three content frames recognized in FDG model, thetic, presentative and categorical. The clausal linearization reflects decisions taken in the formulation of the Interpersonal Level and predominantly represents Topic-oriented content frame in which the constituent in the Topic function occupies the position $P^{I}$, the verb, the $P^{M}$ position, and other remaining constituents occupy the left and right positions of $P^{M}$. Thetic constructions, whose whole clause performs focal and topical function, occupies the $P^{F}$ area, while presentative constructions have the grammatical word 'copula' taking the absolute position $P^{M}$ and the Topic/Focus Noun phrase taking the $P^{F}$ position.
\end{abstract}

Key-words: Word order, thetic construction, presentative construction, categorical construction.

Resumo: A ordenação de constituintes oracionais nas variedades portuguesas é aqui tratada considerando-se três moldes de conteúdo, Tético, Apresentativo e Categorial. A linearização das estruturas oracionais refletem decisões assumidas na formulação do Nivel Interpessoal e configuram predominantemente Molde de Conteúdo Categorial Tópico-orientado, com o constituinte Tópico ocupando a posição $P^{I}$, a palavra verbal, a posição $P^{M}$, e os outros constituintes, as posições à direita e à esquerda de $P^{M}$. Em Construções Téticas, a oração toda, por ser focal, ocupa o domínio de $P^{F}$, já em Construçôes Apresentativas a cópula vazia assume a posição absoluta $P^{M}$, e o sintagma nominal Tópico/Foco posiciona-se em $P^{F}$.

Palavras-chave: ordem de palavras, construção tética, construção apresentativa, construção categorial.

1. Bolsista de Produtividade em Pesquisa CNPq (Proc. No. 301210/2009-8); Bolsista CAPES Estágio Sênior no Exterior (Proc. No. 5784/10-7) 


\section{INTRODUÇ̃̃O}

Tratar da ordenação de constituintes em qualquer língua é sempre um desafio, uma vez que, de um ponto de vista funcional, envolve princípios pragmáticos e semânticos que determinam a colocação dos elementos na oração e nos sintagmas.

Assumimos, com Dik (1997a), que a ordem dos constituintes serve como um dos meios pelos quais relações e funções da estrutura subjacente podem ser formalmente expressas. Assim, a linearização de constituintes na oração nada mais é do que um mecanismo de expressão, de modo que ordens alternativas podem expressar distinções nas estruturas subjacentes dos componentes pragmático e semântico de uma língua particular.

A ordenação de constituintes não é, portanto, uma propriedade profunda das línguas naturais, mas um mecanismo de expressão superficial que, em maior ou menor grau, pode ser empregado para codificar relações subjacentes em sequências atualizadas. Não sendo uma propriedade da estrutura profunda, as estruturas subjacentes de oração das diferentes línguas não diferem necessariamente na ordenação dos constituintes, o que adiciona uma validade trans-sistêmica para a noção de estrutura subjacente e para a adequação tipológica de uma teoria. Segundo Dik (1997a), não há uma única ordem básica para uma determinada língua, mas sim a coexistência de diferentes padrões a serem usados em diferentes condições e para diferentes propósitos. Isso é o que este estudo mostrará na sequência.

Nas gramáticas tradicionais, a ordenação de constituintes é tratada como uma questão estilística, como bem já assinala Barbosa (1881), ao afirmar que todas as construções se reduzem a duas gerais: a direita e a invertida. $\mathrm{Na}$ direita as palavras e as orações seguem a mesma ordem de sua sintaxe, referindo-se cada uma sucessivamente àquela que lhe precede imediatamente, e assim "o sentido nunca fica suspenso, entende-se da maneira que se vai ouvindo ou lendo". Na invertida, pelo contrário, há mudança na ordem da sintaxe, e "as palavras e orações, ou regidas ou subordinadas, vão primeiro que as que regem ou subordinam, e assim o sentido fica suspenso, e só entendemos quando chegamos ao final da oração". Para o autor, no entanto, as duas construções são consideradas naturais, porque ambas são necessárias e usadas em todas as línguas.

Garcia (1982: 262) observa que todas as línguas têm o seu sistema próprio de ordenar termos e orações dentro do período, mas em geral a 
disposição desses elementos está condicionada ao rumo de raciocínio, à sequência lógica, à clareza e à ênfase. Em português a ordem direta consiste em antepor-se o sujeito ao verbo e este aos seus complementos essenciais, "mas a própria gramática admite uma série de exceções”, a que se denomina de modo geral inversão. Há inversão quando qualquer termo está fora da ordem direta, fora da sua posição normal ou habitual, dando "à frase mais vigor e mais energia, o que é o mesmo que dizer mais ênfase, realce ou relevo."

"Dar à frase mais ênfase, realce ou relevo" é visto como resultado de necessidades estilísticas, por isso a colocação de constituintes na sentença é, então, tratada como figuras de linguagem (Cunha e Cintra 2008: 635), mais especificamente como figuras de sintaxe (ou de construção), definidas por Azeredo (2008: 488) como o desvio estilístico que ocorre na organização sintática. As figuras de linguagem envolvidas na alteração da ordem dentro da oração são Hipérbato, Sínquise, Anástrofe e Anacoluto.

Como se vê, os gramáticos, de modo geral, relacionam estilo, ou seja, as escolhas que o falante faz ao dar uma forma linguística às suas intenções comunicativas, a ordenação de constituintes. Isso significa, em outras palavras, que os gramáticos levam em conta aspectos do discurso, ou mais precisamente, aspectos pragmáticos que afetam de alguma maneira a forma dos enunciados.

Com o advento das teorias linguísticas, a ordem de palavras passa a ser vista de outra perspectiva, não mais como estilo, mas sim como um modo de classificação das línguas, sendo, então, tratada de um ponto de vista tipológico, principalmente a partir de Greenberg (1963).

Greenberg (1963) foi o primeiro estudioso a propor uma tipologia sintática, tendo como critério a ordem dos constituintes da sentença. Examinando trinta línguas diferentes, formula uma tipologia com base na posição relativa do sujeito $(\mathrm{S})$, do verbo $(\mathrm{V})$ e do objeto $(\mathrm{O})$. Das seis possibilidades lógicas, há três dominantes: VSO, SVO e SOV. A esses três tipos se associam características sintáticas como o uso de preposições (pr) ou de posposições (po), a posição do adjetivo (adj) e do genitivo $(\mathrm{G})$ em relação ao nome, e o uso de partículas interrogativas e de auxiliares. Formula ainda um número de universais implicacionais do tipo: dado x numa língua particular, então y. Se uma língua tem, por exemplo, a ordem VSO como básica nas orações declarativas, o genitivo sempre seguirá o substantivo regente. Com base nessa tipologia, o português é classificado como 
língua SVO, com preposição (Pr), em que o genitivo e o adjetivo seguem o substantivo $(\mathrm{N}+\mathrm{G}$ e $\mathrm{N}+\mathrm{adj})$.

Propondo uma classificação tipológica alternativa das línguas, com base na relação sujeito/predicado e tópico/comentário, Li e Thompson (1976) consideram a existência de quatro tipos de línguas: a. línguas com proeminência de sujeito, em que a estrutura das sentenças é mais bem descrita como de sujeito-predicado, como, por exemplo, as línguas indoeuropéias; b. línguas com proeminência de tópico, em que a estrutura das sentenças é mais bem descrita como de tópico-comentário, como o chinês; c. línguas com proeminência de tópico e de sujeito, em que coexistem as duas construções, como o japonês; d. línguas sem proeminência de sujeito ou de tópico, em que o sujeito e o tópico se mesclam e não se distinguem mais os dois tipos, como o tagalog.

A ordenação de constituintes na sentença, sob o ponto de vista linguístico, recebe explicações distintas a depender do arcabouço teórico adotado, ou seja, de orientação formalista ou funcionalista, mas preserva um ponto comum: leva em conta a valência do verbo e a ordenação é tratada em termos de $\mathrm{SV}(\mathrm{O})$ ou VS.

Os estudos sobre a ordenação de constituintes no português têm-se inspirado na tipologia da ordem básica, proposta por Greenberg (1963). Desse modo têm-se concentrado na ordenação de constituintes nucleares (obrigatórios), tomando para estudo estruturas de sentenças declarativas com verbos de dois argumentos.

Considera-se a sequência SVO a ordem não-marcada com base na frequência de uso, conforme é possível constatar em Pádua (1960); em Lopes (1981); em Braga (1986) e em Bentivoglio e Braga (1988). A sequência VS, por outro lado, é considerada uma ordem excepcional, pouco frequente, por isso marcada, e tem sido enfocada sob diferentes perspectivas, cada qual apresentando uma explicação própria para o fenômeno.

Pezatti (1992, 1994), por seu turno, defende a existência de dois padrões de ordenação no $\mathrm{PB}$, o padrão $\mathrm{SV}(\mathrm{O})$ preferido por verbos transitivos e intransitivos não-existenciais e o padrão VS, que ocorre com verbos existenciais/apresentacionais. Há assim, segundo a autora, dois tipos de verbos intransitivos para atender a duas necessidades discursivas distintas: o verbo intransitivo existencial atende à necessidade de se introduzir uma entidade 
nova no discurso, ao passo que verbo intransitivo não existencial é usado quando a entidade já é dada. Sendo assim, há dois tipos de verbos intransitivos: os pragmaticamente motivados, selecionados por sua capacidade de introduzir informação nova e os semanticamente motivados, selecionados por seu conteúdo léxico-semântico de um lugar.

Os estudos atuais têm tratado a ordenação de constituintes como resultante de regras, estruturais ou pragmáticas. Mais recentemente, o grupo de pesquisa do Projeto de Gramática do Português Falado (PGPF) dedicou atenção especial à questão da ordem tratando das rupturas de ordem e preenchimentos de fronteiras (cf. Tarallo et al. 2002; Kato et al. 2002; Tarallo 2002; Callou et al. 2002). Castilho (2010: 269), por exemplo, considera haver regras obrigatórias e variáveis governando a ordem dos constituintes no interior da sentença. As obrigatórias são exemplificadas pela ordem de constituintes de sílabas de palavras. A ordem dos constituintes da sentença e do texto exemplifica as regras variáveis.

Como é possível observar, a ordem de palavras em português tem sido objeto de estudo de vários pesquisadores, sob diferentes perspectivas. Este estudo, entretanto, tem como proposta explicar a ordenação de constituintes em português, sob o ponto de vista da Gramática Discursivo-Funcional (Hengeveld e Mackenzie 2008), considerando os três moldes de conteúdo - Tético, Categorial e Apresentativo -, o que permite uma explicação adequadamente tipológica, já que é formulada em termos de regras e princípios que podem ser aplicados a qualquer tipo de língua natural; adequadamente pragmática, uma vez que nos ajuda a entender como as expressões linguísticas podem ser efetivamente usadas na interação comunicativa, e adequadamente psicológica, pois é compatível com o mecanismo psicológico envolvido no processamento de língua natural.

Para isso, como universo de pesquisa, tomamos ocorrências reais de uso, extraídas do corpus oral organizado pelo Centro de Linguística da Universidade de Lisboa, em parceria com a Universidade de Toulouse-le-Mirail e a Universidade de Provença-Aix-Marselha. Tal amostragem recebe o nome de "Português oral" e desenvolveu-se no âmbito do Projeto "Português Falado: Variedades Geográficas e Sociais", do qual resultou um corpus de amostragens de variedades do português falado. ${ }^{2}$

2. Os materiais foram obtidos no endereço h ttp://www.clul.ul.pt/sectores/linguistica_de_corpus/ projecto_portuguesfalado.php 
O texto está organizado em duas partes. Primeiramente são apresentados os pressupostos teóricos, necessários para a compreensão da ordenação de constituintes segundo a Gramática Discursivo-Funcional, que se acham subdivididos em Conteúdo Comunicado, Funções Pragmáticas e Moldes de Conteúdo. A segunda parte é dedicada à ordenação de constituintes propriamente dita, estando subdividida em Tética, Apresentativa e Categorial.

\section{Pressupostos teóricos}

A Gramática Discursivo-Funcional (doravante GDF), embora procure entender a estrutura dos enunciados em seu contexto discursivo, não tem a pretensão de oferecer uma descrição completa do contexto discursivo como um todo e nem é de modo algum um modelo de análise do discurso. No entanto, uma importante característica da GDF é considerar muito seriamente o fato de que os enunciados são produzidos e entendidos no contexto, pois assume que a intenção do falante não surge em um vacuum, mas sim em um multifacetado contexto comunicativo.

De acordo com os princípios estabelecidos na Gramática Funcional (GF) por Dik (1997:6), a GDF, que dela deriva e a expande, representa uma abordagem que leva em conta a natureza situada da comunicação linguística e, por isso, apresenta uma explicação da inter-relação entre linguagem e contexto.

A arquitetura geral da GDF é constituída de quatro componentes: o conceitual, o contextual, o gramatical e o de saída (cf. Figura 1 abaixo).

O Componente Conceitual é pré-linguístico. Nele, a intenção comunicativa (por ex.: solicitação de informação) e a representação mental correspondente (por ex.: o evento ignorado) são relevantes. Por meio da operação de Formulação essas representações conceituais são traduzidas em representações pragmáticas, no Nível Interpessoal, e semânticas, no Nível Representacional. As regras usadas na Formulação são específicas de cada língua. ${ }^{3}$ Como resultado, representações conceituais similares podem receber representações pragmáticas e semânticas diferentes em diferentes línguas.

3. A GDF não pressupõe noções semânticas e pragmáticas universais. 
As regras de formulação fazem uso de um conjunto de primitivos que contêm moldes, lexemas e operadores. As configurações nos níveis Interpessoal e Representacional são traduzidas em estruturas morfossintáticas na Codificação Morfossintática. As regras de Codificação Morfossintática caem em um conjunto de primitivos que contém Padrões Morfossintáticos, Morfemas Gramaticais e Operadores Morfossintáticos. Similarmente, as estruturas dos níveis Interpessoal, Representacional e Morfossintático são traduzidas em estrutura fonológica no Nível Fonológico. As regras de codificação fonológica caem em um conjunto de primitivos que contém Padrões fonológicos, formas supletivas e Operadores Fonológicos.

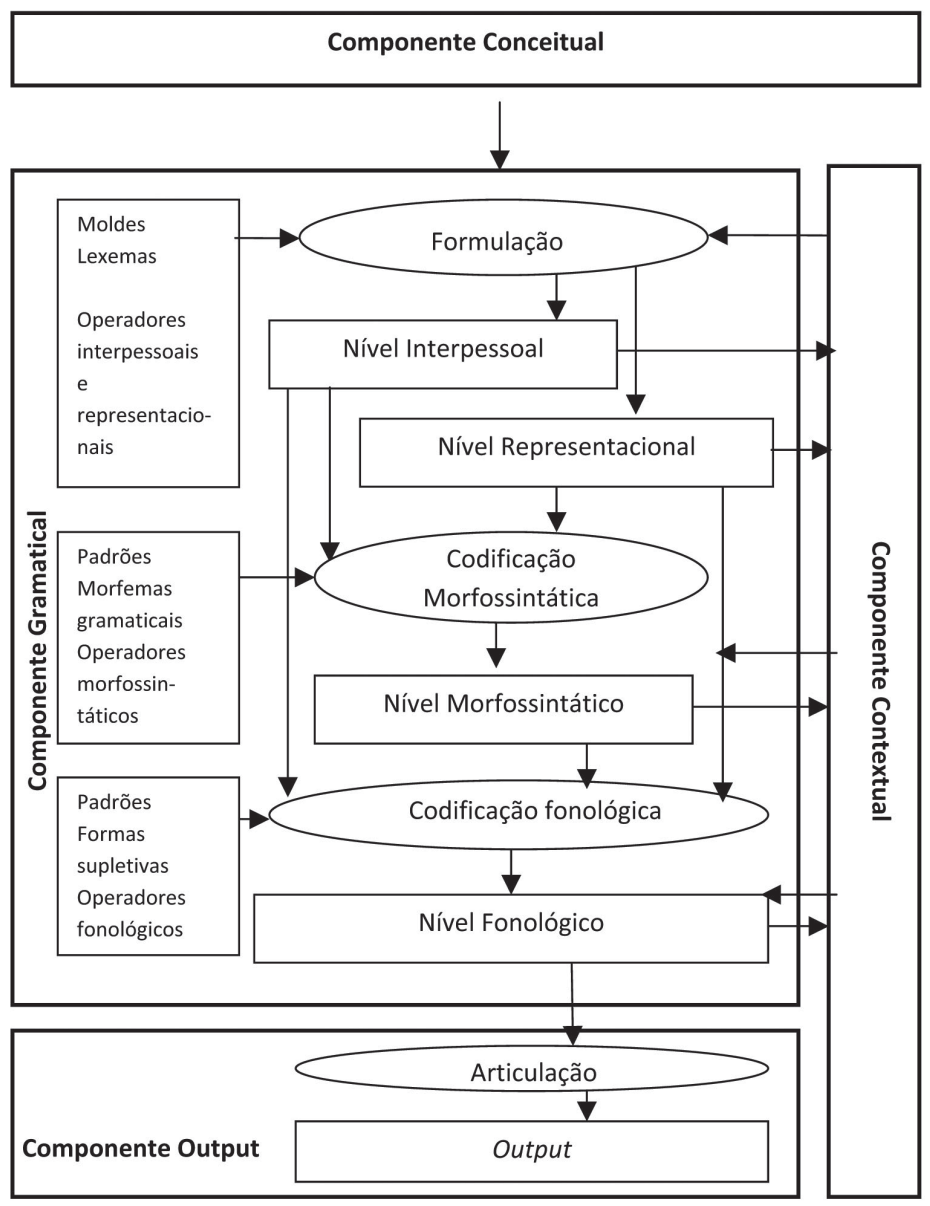

Figura 1. Esboço geral da GDF (adaptado de Hengeveld e Mackenzie 2008:13) 
Ao organizar o Componente Gramatical desse modo, a GDF considera a abordagem funcional de língua em seu extremo lógico: dentro da organização descendente da gramática, a pragmática comanda a semântica, a pragmática e a semântica comandam a morfossintaxe e a pragmática, a semântica e a morfossintaxe comandam a fonologia.

O Nível Fonológico de representação é o input para a operação de Articulação, que, no caso de um Componente de Saída Acústico (diferentemente da escrita ou da língua de sinais), contém regras fonéticas necessárias para alcançar um enunciado adequado. A articulação ocorre fora da gramática propriamente dita.

Os vários níveis de representação dentro da gramática alimentam o Componente Contextual, capacitando subsequente referência a vários tipos de entidades relevantes para cada um desses níveis uma vez introduzidos no discurso. O Componente Contextual alimenta as operações de formulação e codificação, ao disponibilizar antecedentes, referentes visíveis e participantes do ato de fala que podem influenciar a composição do Ato Discursivo subsequente. Para criar uma especificação contextual, o Ouvinte tem de reconstruir todos os níveis de representação com base no output real da gramática, i. e., o enunciado fonético. A GDF parte da perspectiva da produção linguística e concentra-se no Componente Gramatical.

O Componente Gramatical é representado por meio de elipses, caixas e retângulos: elipses são reservadas para operações; caixas, para primitivos, e retângulos, para níveis de representação. A operação de formulação no Componente Gramatical converte a intenção comunicativa em representações pragmáticas e semânticas, nos níveis Interpessoal e Representacional, respectivamente. No próximo estágio, operações de codificação, por seu turno, convertem essas representações pragmáticas e semânticas em representações morfossintáticas e fonológicas; essas representações constituem o output da gramática e ao mesmo tempo o input para a operação final de articulação, cujo resultado é a expressão linguística.

Os quatro níveis de representação são hierarquicamente estruturados em camadas de vários tipos. A mais alta camada do Nível Interpessoal é o Movimento, que consiste de um ou mais Ato Discursivo; um Ato discursivo é, por sua vez, organizado sobre um esquema ilocucionário, que contém dois Participantes do Discurso, falante e ouvinte, e o Conteúdo Comunicado, composto, por seu turno, de Subatos de Referência e de Atribuição. 
No Nível Representacional a unidade mais alta é o conteúdo proposicional (p), que contém um ou mais episódio, que, por sua vez, contém um ou mais estado-de-coisas, organizado em propriedade, indivíduo, lugar, tempo, modo, quantidade e razão.

O Nível Morfossintático é responsável pelas representações estruturais em termos de propriedades lineares das unidades linguísticas e, similarmente a outros níveis, é hierarquicamente organizado em expressão linguística, oração, sintagma e palavra.

Considerando que a produção começa com as intenções comunicativas, que são processadas de cima para baixo, a eficiência do modelo da GDF é proporcional ao modo como ela reflete a produção linguística. Na Figura 1 acima, os percursos são representados por flechas. As flechas horizontais referem-se ao conjunto de primitivos de várias operações. A implementação dinâmica, que é representada por flechas verticais, indica o Princípio de Primazia da Profundidade e o Princípio de Profundidade Máxima, ambos destinados a acelerar a implementação da gramática. O Princípio de Primazia da Profundidade afirma que a informação de certo nível é enviada para um nível mais baixo logo que o input informacional necessário para esse nível estiver completo, enquanto o Princípio de Profundidade Máxima assegura que somente os níveis de representação relevantes para a construção (de certo aspecto) do enunciado são usados na produção desse (aspecto do) enunciado (Hengeveld 2005:73).

Cada um dos níveis de representação dentro do Componente Gramatical é estruturado de modo próprio. O que todos eles têm em comum é uma organização hierarquicamente ordenada em camada, ou seja, são dispostos numa estrutura em camadas. Cada camada é composta de um Núcleo (obrigatório), que pode ser restringido por um Modificador (opcional), especificado por um Operador e ter uma Função. Núcleos e Modificadores $\left(\sum, \sigma\right)$ representam estratégias lexicais, enquanto operadores $(\pi)$ e funções $(\Phi)$ representam estratégias gramaticais. Função é sempre relacional e ocorre entre unidades da mesma camada, já o operador se aplica a uma unidade em si mesma.

\subsection{O Conteúdo Comunicado}

Para explicar a ordenação de constituintes com base em moldes de conteúdo, precisamos entender primeiramente como se organizam as 
camadas do Nível Interpessoal, principalmente a camada do Conteúdo Comunicado.

Nossa unidade de análise é o Ato Discursivo, aqui entendido como a unidade básica do discurso, ou seja, a menor unidade linguística do comportamento comunicativo que corresponde a uma unidade de entonação. Assim sendo, a unidade de análise constitui-se de quatro componentes: uma Ilocução, que indica a finalidade do ato verbal, um Falante que se dirige a um Destinatário e um conteúdo a ser comunicado, que contém tudo o que o Falante deseja evocar na sua interação com o Destinatário. Em termos acionais corresponde ao que Searle (1969) denomina "ato representacional" e corresponde às escolhas que o Falante faz para evocar um quadro do mundo externo sobre o qual deseja falar. O Conteúdo Comunicado é a unidade dentro da qual ocorre o mapeamento do Nível Representacional.

O Conteúdo Comunicado de um Ato Discursivo Declarativo pode ser inteiramente novo para o Destinatário ou conter informações novas e familiares. Às vezes, no entanto, a informação pode já ser familiar para o Destinatário, e a intenção do Falante é relembrá-lo ou, por alguma razão, afirmar o óbvio.

Cada Conteúdo Comunicado contém um ou mais Subatos, assim chamados porque são hierarquicamente subordinados ao Ato Discursivo e cada um é uma forma de ação comunicativa do Falante. O Conteúdo Comunicado pode ser representado como em (01), em que $\pi$ indica operador; C, Conteúdo Comunicado; T, Subato de Atribuição; R, Subato de Referência; $\sum$, modificador; e $\mathrm{N}$, número não específico:

(01) $\left(\pi \mathrm{C}_{1}:\left[\ldots\left(\mathrm{T}_{1}\right)^{\mathrm{N}}\left(\mathrm{R}_{1}\right)^{\mathrm{N}} \ldots\right]\left(\mathrm{C}_{1}\right): \sum\left(\mathrm{C}_{1}\right)\right)$

Os Subatos contidos em um Conteúdo Comunicado são de dois tipos: Subato de Atribuição (T) e Subato de Referência (R). O primeiro expressa uma tentativa do Falante de evocar uma propriedade. Já o segundo, constitui uma tentativa do Falante de evocar um referente, ou seja, um conjunto nulo, único ou múltiplo de entidades. Um Conteúdo Comunicado deverá conter pelo menos um Subato. Não há um número máximo, mas o número de Subatos dependerá do tipo de evento comunicativo. A fala informal, por exemplo, tende a ter Conteúdos Comunicados simples, enquanto a escrita formal permite combinações complexas. 
Os Subatos veiculam funções pragmáticas e o núcleo de Conteúdos Comunicados pode ser formulado em termos de configurações de funções pragmáticas, denominadas moldes de conteúdo. Trataremos primeiramente das funções pragmáticas, para depois dirigirmos nossa atenção ao molde de conteúdo.

\subsection{Funções pragmáticas}

A pragmática, na GDF, refere-se ao modo como o falante modela as suas mensagens em relação às expectativas que tem do estado mental do ouvinte. Isso determina as partes de uma unidade linguística que serão apresentadas como particularmente salientes, as que serão escolhidas como ponto de partida do falante e as que serão consideradas compartilhadas pelo falante e pelo ouvinte. A influência desses aspectos sobre a estrutura das unidades linguísticas recebe o nome de função pragmática, que se aplica ao Conteúdo Comunicado ou a um de seus constituintes. A GDF distingue três funções pragmáticas, Foco, Tópico e Contraste, que são linguisticamente marcadas, e têm como contraparte, que raramente é marcada nas línguas, respectivamente o fundo (background), o comentário e a sobreposição (overlap). Neste trabalho interessa-nos apenas as funções de Tópico e Foco, de que trataremos a seguir.

\subsubsection{Foco}

Segundo Dik (1989), parcialmente correspondente à distinção dado/ novo é a dimensão da focalidade, que se refere a porções de informação mais salientes ou importantes em relação às mudanças que o falante deseja efetuar no conhecimento pragmático do destinatário.

A função Foco de uma expressão linguística é a informação relativamente mais importante ou saliente num dado contexto de interação verbal, e avaliada pelo Falante como essencial para ser integrada na informação pragmática do Destinatário. A informação focal se refere, então, às mudanças que o Falante deseja provocar na informação pragmática do Destinatário. Dessa forma, deve haver sempre alguma diferença entre a informação pragmática do Falante e o quadro que ele faz da informação 
pragmática do Destinatário. A informação focal é apresentada como "nova" para o Destinatário.

A GDF (Hengeveld e Mackenzie 2008), baseando-se em Dik (1989), considera que, na interação, a função Foco sinaliza a seleção estratégica do Falante de informação nova ou para preencher uma lacuna na informação do Destinatário, ou para corrigir uma informação do Destinatário; em outros termos, constitui uma instrução de atualização do Destinatário. Na GDF, a função Foco só é considerada quando é linguisticamente relevante, ou seja, quando são usados meios linguísticos para indicar que alguma parte da Expressão Linguística constitui informação nova relevante.

Uma forma de indicar a função pragmática Foco, em português, é a construção denominada por Braga (2009) de Foco-ser, conforme exemplificado em (02), que assinala informação nova, e em (03), que corrige uma informação que o falante considera obscura.

(02) comecei a pintar, principalmente foi com aquarela

(Moç83:CantarPintar36)

(03) mas ficava o pão melhor, era, com a batata?

PT94:AmassarCozer:93

A ocorrência (05) apresenta no discurso um constituinte pela primeira vez, ou seja, fornece uma nova informação (com aquarela), considerada pelo Falante muito importante para o Destinatário acrescentar à sua informação pragmática, já em (06), o Falante solicita do Destinatário uma correção em sua informação pragmática, ao responder a pergunta contida no Ato Interrogativo ficava o pão melhor, era, com a batata? Em todos esses casos, o verbo ser flexionado no mesmo modo e tempo do verbo principal constitui um operador de Foco.

\subsubsection{Tópico}

Outra dimensão da estrutura informacional é a dicotomia TópicoComentário. Como se sabe, Tópico é um conceito fundamental de vários modelos linguísticos, principalmente funcionalistas.

Chafe (1976) classifica Tópico em três tipos: o inglês, o chinês e o do Caddo. Para ele, no entanto, o tópico real é o do chinês, já que estabelece um esquema espacial, temporal ou individual dentro do qual a predicação 
principal se mantém, de modo a limitar-lhe a aplicabilidade a certo domínio restrito. No inglês, segundo o autor, o tópico é simplesmente um foco de contraste que tem de ser, por alguma razão, colocado no início da sentença. Outra forma de manifestação de tópico é como um sujeito prematuro, ou seja, um sujeito escolhido antecipadamente ao esquema de caso e, portanto, não homogeneamente integrado na sentença que segue.

Para Dik (1989), no entanto, o Tópico é um conceito discursivo, pois qualquer discurso, tomado no sentido mais amplo de texto coerente, "fala" necessariamente a respeito de entidades. É essa entidade que Dik denomina Tópico-Discursivo. Um discurso pode ter diferentes Tópicos-Discursivos, alguns mais centrais do que outros, por isso são hierarquicamente organizados. Em sentido abstrato, pode-se considerar que um discurso contém um "estoque de tópicos", vazio no início, e que vai gradualmente sendo preeenchido com Tópicos-Discursivos, conforme são introduzidos no discurso. Alguns Tópicos têm vida curta e desaparecem, outros são mais pervasivos e permanecem ao longo do discurso. A função Tópico apresenta, então, a entidade sobre a qual se fala numa dada situação; em outras palavras, na predicação nós dizemos alguma coisa sobre o Tópico.

Hengeveld e Mackenzie (2008), por seu turno, consideram que a função Tópico, quando relevante numa língua, não é complementar a Foco, mas parte da dimensão Tópico-Comentário. Assim definem Tópico como a função pragmática atribuída a um constituinte para assinalar como o conteúdo comunicado se relaciona ao registro construído gradualmente no componente contextual.

Hannay e Martínez-Caro (2008:60) acrescentam que o Tópico fornece um tipo específico de orientação para o estoque de informação nova a ser apresentada. Como é possível observar, essa definição se aproxima da de Chafe (1976).

Tópico é ainda entendido como um reflexo linguístico de uma instrução para o Destinatário resgatar uma informação (cf. Hengeveld e Mackenzie 2008:92). Dessa maneira, Tópicos contêm informação que pode ser inferida do contexto ou informação que pode ser ativada na memória episódica dos interlocutores. A função básica do Tópico é, então, relacionar o Conteúdo Comunicado a informações existentes no Componente Contextual, como exemplificam ocorrências como (04) e (05), em que o uso do artigo definido a e do pronome isto, respectivamente, reflete a instrução do Falante para o 
Destinatário recuperar a informação existente no Componente Contextual e torna explícito que os outros Subatos, de alguma forma, desenvolverão a informação no Componente Contextual.

(04) a criança cresceu (Ang97:ContoTradicional:14)

(05) e isto é um aspecto importante (Ang97:EnsinoAngola:48)

Uma vez que o Componente Contextual contém também informações sobre as coordenadas espacial e temporal de ocorrência do estado-de-coisas, a função Tópico pode ser atribuída a Subatos que servem para indicar o cenário (setting) do estado-de-coisas evocado, como a localização espacial, conforme (06), e a localização temporal, em (07).

(06) lá criaram todo o processo de socialização (CV95:IlhaFogo:123)

(07) e agora recomeçam uma vida nova nessas zonas (CV95:IlhaFogo:128)

A função Tópico é sempre atribuída a Subatos dentro do Conteúdo Comunicado, e, da mesma forma que acontece com o Foco, só deve ser considerada se houver repercussão na realização linguística do Ato Discursivo. Em português, como mostram os exemplos acima, o Tópico é marcado pela posição no campo inicial da oração, à esquerda da palavra verbal, denominada PI.

\subsection{Moldes de Conteúdo}

Como já observado, Conteúdos Comunicados contêm Subatos, que podem evocar propriedades ou referentes. No primeiro caso denominamse Subatos Atributivos, e no segundo, Subatos Referenciais. Esses Subatos podem se combinar com funções pragmáticas para preencher a posição de núcleo do Conteúdo Comunicado. Essas combinações, não hierarquicamente organizadas, são chamadas Moldes de Conteúdo. A distribuição de Tópico e Foco determina três tipos de configurações: Tética, Categorial e Apresentativa.

a) Tética:

A sentença tética é constituída por um ou mais Subatos, com função pragmática Foco. Esse tipo de sentença expressa um juízo associado a apenas 
um ato cognitivo, o de «reconhecimento ou rejeição material de um juízo» (Mateus et al. 2003:318), e apresenta um evento, estado ou situação globalmente. Pezatti (1992) denomina de frase comentário, uma vez que descreve uma situação, sem especificar qualquer elemento como ponto de vista ou ponto de partida do fluxo de atenção. A informação é dada globalmente, como um todo. A configuração de uma sentença Tética é representada em (08), em que SA indica Subato e N, um número não específico de Subatos, e exemplificada em (09).

(08) $\left[(\mathrm{SA})^{\mathrm{N}}\right]_{\mathrm{FOC}}$

$\begin{array}{cc}\mathrm{T} & \mathrm{R} \\ \text { [acabou } & \text { o ensino rudimentar }]_{\mathrm{FOC}}\end{array}$

(Ang97:EnsinoAngola:46)

b) Categorial

Afirmações categoricas caracterizam-se pela presença tanto de um Tópico quanto de um Foco, com uma configuração conforme representado em (10).

(10) $\left[(\mathrm{SA})_{\mathrm{TOP}}(\mathrm{SA})^{\mathrm{N}}(\mathrm{SA})_{\mathrm{FOC}}\right]$

O inventário de moldes é específico de cada língua. Há línguas orientadas para Tópico, como o Tidore, e línguas orientadas para Foco, como o Kisi. No primeiro caso o molde é representado em (11), e no segundo, em (12).

(11) Categorial Tópico-orientada

$\left[(\mathrm{SA})^{\mathrm{N}}(\mathrm{SA})_{\text {TOP }}\right]$

(12) Categorial Foco-orientada

$\left[(\mathrm{SA})^{\mathrm{N}}(\mathrm{SA})_{\mathrm{FOC}}\right]$

\section{c) Apresentativa}

Sentenças apresentativas, conforme representada em (13), servem comumente para indicar a emergência de uma entidade referencial no discurso. Nos termos de Dik (1989, 1997), introduzem no discurso um tópico novo. O tópico novo combina propriedades da dimensão de topi- 
calidade e focalidade: é focal porque introduz uma entidade no discurso, e tópico, uma vez que introduz uma entidade que se relaciona ao comentário construído gradualmente no componente contextual. Vale de exemplo a ocorrência (14).

(13) $\left[(\mathrm{SA})^{\mathrm{N}}(\mathrm{SA})_{\text {TOPFOC }]}\right.$

$$
\begin{aligned}
& {\left[\mathrm{R}_{\mathrm{TOPFoc}}\right]} \\
& \text { são } \\
& \text { milhöes de pessoas que se deslocam } \quad \text { (Ang97:Guerra e Ambiente:32) }
\end{aligned}
$$

Determinados os três tipos de molde de conteúdo, passemos à ordenação de constituintes no português.

\section{ORdenAÇÃO DE CONSTITUINTES EM PORTUGUÊS}

Sob a luz da GDF, a ordenação de constituintes está relacionada ao Nível Morfossintático. Esse nível trata dos aspectos estruturais de uma unidade linguística e tem como tarefa tomar o input duplo vindo dos níveis Interpessoal e Representacional e fazê-lo emergir numa única representação estrutural, que, por sua vez, se converterá, no Nível Fonológico, num constructo fonológico, que será, finalmente, o input para o articulador, o Componente de Saída de todo o modelo. Em vista dessa função, muito do que ocorre no Nível Morfossintático é funcionalmente motivado: princípios de ordenação são motivados pelos princípios de Iconicidade, Integridade de Domínio e pela Preservação de Relações de Escopo. Entretanto, deve-se levar em conta que esse nível tem seus próprios princípios de organização, que podem não ser funcionalmente motivados. A camada mais alta do Nível Morfossintático é a Expressão Linguística (Le), ou seja, qualquer conjunto de pelo menos uma unidade morfossintática; se houver mais de uma unidade dentro da Expressão Linguística, elas terão as mesmas propriedades morfossintáticas. As unidades que se combinam para formar a Expressão Linguística são: Orações, Sintagmas ou Palavras.

Dada a sistemática organização descendente da GDF, a ordenação de elementos começa com a expressão morfossintática das partes hierarquicamente organizadas nos níveis Interpessoal e Representacional, iniciando pelas camadas mais altas, passando pelas mais baixas até chegar ao conteúdo 
e moldes de predicação. O Nível Morfossintático contém os padrões de moldes hierárquicos e não-hierárquicos. Posições obrigatórias nos padrões para as quais não há material disponível serão preenchidas com elementos vazios (dummies).

Como já fica subentendido, são hierárquicos os constituintes que subordinam ou são subordinados a outros constituintes. Isso significa que pertencem a camadas diferentes. Na ordenação hierárquica, que é baseada em considerações de escopo, são atribuídas posições com fluxo descendente a elementos hierarquicamente relacionados. Os não-hierárquicos, denominados de constituintes configuracionais, por outro lado, pertencem à mesma camada e têm o mesmo estatuto dentro da oração. Na ordenação não-hierárquica, que se baseia em considerações de alinhamento, os elementos de configuração relacional, tais como os de relação predicadoargumento ou de ou núcleo-modificador, são ordenados com base em suas propriedades pragmáticas, semânticas e/ou morfossintáticas, dependendo da língua sob consideração. Isso fica mais claramente explícito em uma sentença como (15).

(15) por exemplo, em S. Vicente, isso já não acontece dessa maneira (CV95:Raparigas:76)

Nessa oração, os elementos configuracionais (não hierárquicos) são isso, já, acontece, dessa maneira, por pertencerem à estrutura nuclear: acontecer é o predicado de um lugar que seleciona um argumento inativo representado por isso. Essa predicação nuclear é especificada pelo operador fasal já, que indica a relação entre o ponto de referência temporal e a fase do desenvolvimento do estado-de-coisas, e restringida pelo modificador de Modo dessa maneira. Não há prioridade entre esses constituintes, o que já não acontece com não, em $S$. Vicente e por exemplo. O operador de polaridade não nega todo o estado-de-coisas isso já acontece; o modificador em S. Vicente, por outro lado, restringe o estado-de-coisas, localizando-o espacialmente. Já o constituinte por exemplo escopa todo o estado-de-coisas em S. Vicente, isso já não acontece dessa maneira, modificando o Ato discursivo, uma vez que indica o estatuto desse Ato dentro do Movimento.

Dessa forma, para entendermos a linearização de constituintes em português, é necessário considerar que cada camada da estrutura oracional terá obrigatoriamente um Núcleo, um Modificador, que é opcional e 
restringe o núcleo, um Operador que especifica por meio gramatical esse núcleo e, possivelmente, uma função, que é sempre relacional e ocorre entre unidades da mesma camada.

É importante ainda levar em conta que Núcleos e Modificadores constituem estratégias lexicais, ou seja, pertencem ao léxico daquela língua particular, enquanto Operadores e funções são estratégias gramaticais; em outras palavras, pertencem ao "mundo linguístico".

Tomando como suporte teórico Hengeveld e Mackenzie (2008), para explicar a linearização de constituintes em português, é necessário considerar três posições básicas, que denominamos $\mathrm{P}^{\mathrm{I}}$, para a posição inicial, $\mathrm{P}^{\mathrm{M}}$, posição medial e $\mathrm{P}^{\mathrm{F}}$ para a posição final, e várias posições relativas derivadas dessas três. As duas posições periféricas $\left(\mathrm{P}^{\mathrm{I}}\right.$ e $\left.\mathrm{P}^{\mathrm{F}}\right)$ são psicologicamente salientes, enquanto a posição medial é menos saliente e depende do número de constituintes que uma oração pode conter. As posições relativas $\left(\mathrm{P}^{\mathrm{I}+\mathrm{n}}, \mathrm{P}^{\mathrm{M}+/-\mathrm{n}}\right.$ e $\left.\mathrm{P}^{\mathrm{F}-\mathrm{n}}\right)$ só podem ser preenchidas quando a posição absoluta já estiver preenchida.

\begin{tabular}{|l|l|l|l|l|l|l|l|l|l|l|}
\hline $\mathrm{P}^{\mathrm{I}}$ & $\mathrm{P}^{\mathrm{I}+1}$ & $\mathrm{P}^{\mathrm{I}+\mathrm{n}}$ & $\mathrm{P}^{\mathrm{M}-\mathrm{n}}$ & $\mathrm{P}^{\mathrm{M}-1}$ & $\mathrm{P}^{\mathrm{M}}$ & $\mathrm{P}^{\mathrm{M}+1}$ & $\mathrm{P}^{\mathrm{M}+\mathrm{n}}$ & $\mathrm{P}^{\mathrm{F}-\mathrm{n}}$ & $\mathrm{P}^{\mathrm{F}-1}$ & $\mathrm{P}^{\mathrm{F}}$ \\
\hline
\end{tabular}

A linearização de constituintes em português é adequadamente explicada considerando-se que a Oração pode dispor, em princípio, de três posições - $\mathrm{P}^{\mathrm{I}}, \mathrm{P}^{\mathrm{M}}$ e $\mathrm{P}^{\mathrm{F}}$ - cada uma delas especializada para determinados tipos de constituintes.

Obedecendo ao Princípio de Proximidade do Núcleo (Dik 1997a), os constituintes nucleares do domínio da oração colocam-se o mais próximo possível um do outro. Assim, $\mathrm{P}^{\mathrm{M}}$ é reservada para os constituintes configuracionais (não hierárquicos), enquanto as posições periféricas são preenchidas por constituintes hierárquicos, que tomam por escopo a camada dos constituintes configuracionais.

As posições de $\mathrm{P}^{\mathrm{M}}$ abrigam constituintes configuracionais, ou seja, funções, modificadores e operadores pertencentes à camada da propriedade configuracional, com a palavra verbal assumindo sempre a posição $\mathrm{P}^{\mathrm{M}}$. No campo de $\mathbf{P}^{\mathrm{I}}$ alocam-se os constituintes com função pragmática Tópico, e, quando houver, os modificadores e operadores do Nível Interpessoal e do Nível Representacional. Para o campo de $\mathbf{P}^{\mathrm{F}}$ vão os constituintes com 
função pragmática Foco, os modificadores das camadas mais altas do Nível Representacional e constituintes estruturalmente complexos.

Postulamos que, em português, a ordenação dos constituintes configuracionais apresenta uma orientação centrífuga e se processa com a colocação da palavra verbal em posição medial, seguida da colocação dos outros constituintes configuracionais, dirigindo-se à direita e à esquerda, conforme representado graficamente em (16).

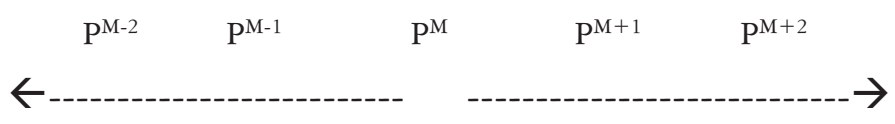

Os constituintes configuracionais argumentais bem como os modificadores são colocados à direita de $\mathrm{P}^{\mathrm{M}}$, e só mudam de posição se houver interferência da dimensão pragmática, como a atribuição de função pragmática Tópico e Foco aos Subatos, ou seja, vai depender do molde de conteúdo escolhido pelo Falante na formulação da Expressão Linguística para alcançar seu objetivo comunicativo: Tético, Categorial ou Apresentativo.

\subsection{Construção Tética}

Como vimos, a sentença Tética é constituída por um ou mais Subatos, sendo todos eles focais. O conteúdo comunicado é dado globalmente, como um todo; não há um Tópico, e toda sentença é focal, conforme demons$\operatorname{tra}(17)$.

$$
\begin{array}{lcl}
{\left[\mathrm{T}_{\mathrm{i}}\right.} & \left(+\mathrm{id}+\mathrm{sR}_{\mathrm{i}}\right) & \left.\mathrm{T}_{\mathrm{j}}\right]_{\text {FOC }} \\
\text { caiu } & \text { tudo } & \text { abaixo }
\end{array}
$$

PT95:Bruxedos:23

Nesse tipo de construção o Subato Referencial é marcado pelo operador $(+\mathrm{id})$, uma vez que o Falante pressupõe que o referente é identificável para o Destinatário, e pelo operador $(+s)$, já que é específico para o próprio Falante.

Construções Téticas, no Nível Representacional, correspondem a moldes de predicação de propriedade de zero lugar, conforme exemplifica (18); de um lugar, como se vê em (19), que tem sido denominada construção VS, porque o sujeito, não sendo o Tópico, posiciona-se depois do verbo. 

começou a relampejar, Moç86:Chuva:32 já aconteceram vinte e um, vinte e uma erupção CV95:IlhaFogo:05

Nessas construções a palavra verbal e seu argumento, quando houver, constituem uma unidade fechada que, ao descrever uma situação, não especifica qualquer elemento como ponto de partida e ponto de vista.

Assim, construções Téticas são marcadas, no Nível Interpessoal, pelos operadores de identificabilidade $[+\mathrm{id}+\mathrm{s}]$, que se manifestam no Nível Morfossintático por pronomes, artigos definidos ou numerais. No Nível Representacional, essas construções correspondem a moldes de predicação de propriedade de zero e um lugar, conforme representam (18) e (19) respectivamente. No Nível Morfossintático, responsável pela linearização dos constituintes, a oração toda, por ser focal (informação vinda do Nível Interpessoal), vai para o domínio de $\mathrm{P}^{\mathrm{F}}$. Assim o sintagma verbal ${ }^{4}$, em (18), assume a posição absoluta $\mathrm{P}^{\mathrm{F}}$; em (19), por outro lado, a ordenação começa pela posição absoluta $\mathrm{P}^{\mathrm{F}}$, que será ocupada pelo constituinte mais à direita, o Sintagma Nominal vinte e uma erupção, e os outros constituintes ocuparão as posições relativas à esquerda de $\mathrm{P}^{\mathrm{F}}, \mathrm{P}^{\mathrm{F}-1} \mathrm{e} \mathrm{P}^{\mathrm{F}-2}$.

$$
\begin{aligned}
& {[\mathrm{T}]_{\mathrm{FOC}}} \\
& \mathrm{P}^{\mathrm{F}} \\
& \text { começou a relampejar }
\end{aligned}
$$

Moç86:Chuva:32

$$
\begin{array}{lll}
{[} & \mathrm{T} & (+\mathrm{id}+\mathrm{sR})]_{\mathrm{FOC}} \\
\mathrm{P}^{\mathrm{F}-2} & \mathrm{P}^{\mathrm{F}-1} & \mathrm{P}^{\mathrm{F}} \\
\text { já } & \text { aconteceram } & \text { vinte e um, vinte e uma erupção } \\
\end{array}
$$

O padrão de ordenação para construção tética é representada em

(20) NI: $\left[(\mathrm{SA})^{\mathrm{N}}\right]_{\mathrm{FOC}}$

NM: $P^{\mathrm{F}-\mathrm{N}} \mathrm{P}^{\mathrm{F}}$

Como se observa, essas construções denominadas frase-comentário por Pezatti (1992), incluem estruturas, como a anteposição do verbo (Tarallo e

4. O sintagma verbal terá sua própria ordenação de constituintes. 
Kato 1989) e comentários de ambientes (Berman 1980). Pezatti (1992) observa que esse tipo de estrutura, por veicular uma informação globalmente, numa única unidade entonacional, sem ponto de partida e nem ponto de vista, permite ao falante sustentar, ampliar ou comentar a linha principal do discurso, por isso constitui oração de Fundo ${ }^{5}$, já que contribuem para a descrição ou montagem do cenário no desenvolvimento do discurso.

\subsection{Construção Apresentativa}

Construções Apresentativas, como vimos, dispõem de um Subato veiculando concomitantemente as funções de Tópico e Foco. Servem comumente para indicar a emergência de uma entidade referencial no discurso. Sendo assim, caracterizam-se por apresentar o Subato tópico e focal marcado pelo operador (-id), uma vez que o Falante pressupõe que o referente não é identificável para o Destinatário, como exemplifica (21).

$$
\text { e tem } \quad \begin{aligned}
& {\left[\left(-\mathrm{idR}_{\mathrm{i}}\right)\right]_{\text {TOPFoc }}} \\
& \text { um banheiro e uma sala } \quad \text { (Bra80:Fazenda:18) }
\end{aligned}
$$

Construções Apresentativas, também referidas como construções VS, contêm somente um Subato Referencial, cujo operador de identificabilidade [-id +s] manifesta-se no Nível Morfossintático por meio de pronomes e artigos indefinidos. No Nível Representacional, essa construção corresponde geralmente ao molde de predicação de Existência. Esse tipo de predicação contém somente uma unidade semântica, que não é argumento de nenhum predicado. Para marcar o tempo, é então introduzida uma cópula vazia como haver, ter ou ser, exemplificadas em (22), (23) e (24) respectivamente.

No Nível Morfossintático, a palavra verbal ocupa a posição absoluta $\mathrm{P}^{\mathrm{M}}$, e o Sintagma Nominal, correspondente à unidade semântica do Nível Representacional e ao Subato Referencial, que acumula concomitantemente as funções de Tópico e Foco no Nível Interpessoal, assume a posição final $\left(\mathrm{P}^{\mathrm{F}}\right)$.

5. Nos termos de Hopper e Thompson (1980), a parte do discurso que não contribui imediata e crucialmente para os objetivos do falante, mas que apenas sustentam, ampliam ou comentam o aspecto principal são chamadas 'fundo' (background). Em contraste, o material que fornece os pontos principais do discurso, a linha orientadora da comunicacão chama-se 'figura' (foreground). 


$$
\begin{array}{cc} 
& \multicolumn{1}{c}{\left[\left(-\mathrm{idR}_{\mathrm{i}}\right)\right]_{\text {TOPFOC }}} \\
\mathrm{P}^{\mathrm{F}} & \multicolumn{1}{c}{\mathrm{P}^{\mathrm{M}}} \\
\text { há } \quad \text { um projecto para incentivar as crianças } & \text { (CV95:Colecionismo:106) } \\
& \text { nesse capítulo }
\end{array}
$$

$$
\begin{array}{lc} 
& {\left[\left(- \text { idR }_{\mathrm{i}}\right)\right]_{\text {TOPFOC }}} \\
\mathrm{P}^{\mathrm{M}} & \mathrm{P}^{\mathrm{F}} \\
\text { tinha } & \text { uma senzala }
\end{array}
$$

$$
\mathrm{P}^{\mathrm{M}} \stackrel{\left[\left(-\mathrm{idR}_{\mathrm{i}}\right)\right]_{\text {TOPFOC }}}{\mathrm{P}^{\mathrm{F}}}
$$

são milhões de pessoas que se deslocam (Ang97:Guerra e Ambiente:32)

O padrão de ordenação para construção Apresentativa é representado em (25):

$\begin{array}{ll}\text { (25) NI: } & {\left[(\mathrm{SA})_{\mathrm{TOPFOC}^{-}}\right]} \\ \text {NM: } \quad \mathrm{P}^{\mathrm{M}} \mathrm{P}^{\mathrm{M}+\mathrm{N}} \mathrm{P}^{\mathrm{F}-\mathrm{N}} \mathrm{P}^{\mathrm{F}}\end{array}$

Ferrari (1990), ao enfocar as orações apresentacionais/existenciais com ter e ser, conclui que as orações existenciais com ter introduzem novos membros de uma dada classe, enquanto as com ser apresentam novas propriedades qualitativas de certos membros/classes ou relacionam algum efeito produzido pelo dado membro/classe. Pezatti (1992), por seu turno, observa que essas construções introduzem um novo referente no discurso, que pode tanto fornecer material de suporte para continuação do discurso, quanto ser abandonado, servindo meramente para montar o cenário do discurso em desenvolvimento.

\subsection{Construção Categorial}

Afirmações categoriais, como assinalado, podem ser orientadas para o Tópico ou para o Foco. Postulamos que o português é uma língua orientada para o Tópico, tendo então a configuração $\left[(\mathrm{SA})^{\mathrm{N}}(\mathrm{SA})_{\text {TOP }}\right]$, como mostraremos a seguir. 
Muitos estudiosos, dentre os quais se destacam Pádua (1960), Lopes (1981), Braga (1986), Pontes (1987), Bentivoglio e Braga (1988), Decat (1989), Berlinck (1989), Pezatti (1992), entre outros, já observaram que o português é uma língua SVO.

Pezatti e Camacho (1997), seguindo Dik (1981), ao investigar o português brasileiro, mostram que, no domínio da Oração, essa língua conta com dois padrões de ordenação de constituintes que configuram os esquemas simplificados $\mathrm{P} 1 \mathrm{VS}$ e $\mathrm{P}_{\mathrm{SVO}}{ }^{6}$. Consideram ainda que o português, no passado, se enquadrava no padrão posposicional VSO, o que pode ser comprovado pelas estruturas VS remanescentes. No entanto, diacronicamente, a atribuição da função pragmática Tópico ao sujeito o leva para a posição inicial da sentença, criando então o padrão SVO e consequentemente outra posição P1 é exigida.

Essa orientação voltada para o Tópico é facilmente observável, uma vez que, excetuando-se as construções Téticas e Apresentativas acima descritas, as sentenças do português apresentam sempre um constituinte Tópico.

A função pragmática Tópico é atribuída a um constituinte para assinalar como o Conteúdo Comunicado se relaciona ao registro de informações construído gradualmente no Componente Contextual. Tópicos contêm informação que pode ser inferida do contexto ou informação que pode ser ativada na memória episódica dos interlocutores.

A função Tópico, em português, é assinalada pela colocação do Subato Tópico no início da oração, ou seja, sempre em posições do domínio de $\mathrm{P}^{\mathrm{I}}$. O canditato mais natural à função Tópico é, sem dúvida, o constituinte configuracional do Nível Representacional que, no Nível Morfossintático, desempenha a função de sujeito. Dessa forma, independentemente do molde de predicação de um, dois e três lugares, no Nível Representacional, o sintagma nominal Tópico assumirá a posição $\mathrm{P}^{\mathrm{I}}$, no Nível Morfossintático, conforme se observa em (26), (27) e (28), respectivamente predicações de um, dois e três lugares.

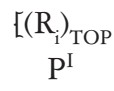

a criança
$\left.\left(T_{i}\right)\right]$

$\mathrm{P}^{\mathrm{M}}$

cresceu
(Ang97:Conto'Tradicional:14)

6. $\mathrm{P} 1$ = posição inicial da oração; $\mathrm{S}=$ sujeito; $\mathrm{V}=$ verbo; $\mathrm{O}=$ objeto. 
(27)

\begin{tabular}{|c|c|c|c|}
\hline & $\left(\mathrm{T}_{\mathrm{i}}\right)$ & $\left.\left(\mathrm{R}_{1}\right)\right]$ & \\
\hline & $\mathrm{P}^{\mathrm{M}}$ & $\mathrm{P}^{\mathrm{M}+1}$ & \\
\hline & protegíamos & essas crianças & (Ang97:Meninos de Rua:72) \\
\hline
\end{tabular}

(28)

\begin{tabular}{|c|c|c|c|c|}
\hline$\left[\left(\mathrm{R}_{\mathrm{i}}\right)_{\mathrm{TOP}}\right.$ & $\left(\mathrm{T}_{\mathrm{i}}\right)$ & $\begin{array}{l}\left(\mathrm{R}_{\mathrm{j}}\right) \\
\mathrm{p}_{\mathrm{M}+1}\end{array}$ & $\left.\left(\mathrm{R}_{\mathrm{j}}\right)\right]$ & \\
\hline $\mathrm{P}^{\mathrm{I}}$ & $\mathrm{P}^{\mathrm{M}}$ & $\mathrm{P}^{\mathrm{M}+1}$ & $\mathrm{P}^{\mathrm{M}+2}$ & \\
\hline toros & $\begin{array}{l}\text { teriam } \\
\text { provocado }\end{array}$ & $\begin{array}{l}\text { graves } \\
\text { consequências }\end{array}$ & ao ambiente & $\begin{array}{c}\text { (Ang)/:Guerra e } \\
\text { Ambiente:01) }\end{array}$ \\
\hline
\end{tabular}

Isso ocorre com todos os tipos de predicação, sejam dinâmicas, como exemplificam os casos acima (26), (27) e (28), sejam não dinâmicas, como a predicação de um lugar em (29), a relacional, em (30), e a classificacional em (31) abaixo, em que o constituinte Tópico assume a posição $\mathrm{P}^{\mathrm{I}}$, a palavra verbal (cópula), a posição $\mathrm{P}^{\mathrm{M}}$, e os outros constituintes configuracionais a posição $\mathrm{P}^{\mathrm{M}+1}$.

$$
\begin{array}{cccc}
\sum \mathrm{A} & {\left[\left(\mathrm{R}_{\mathrm{i}}\right)_{\mathrm{TOP}}\right.} & & \left.\left(\mathrm{T}_{\mathrm{i}}\right)\right] \\
\mathrm{P}^{\mathrm{I}} & \mathrm{P}^{\mathrm{I}+1} & \mathrm{P}^{\mathrm{M}} & \mathrm{P}^{\mathrm{M}+1}
\end{array}
$$

portanto, quer a s(...), a escola secundária, são quer o ensino universitário

são

relativamente (Ang97:Ensino tardios Angola:30)

$$
\begin{aligned}
& {\left[\left(\mathrm{R}_{\mathrm{i}}\right)_{\mathrm{TOP}}\right.} \\
& \mathrm{P}^{\mathrm{I}} \\
& \text { o material }
\end{aligned}
$$

$\begin{array}{ll}\mathrm{P}^{\mathrm{M}} & \\ & \text { é } \\ & \\ & \mathrm{P}^{\mathrm{M}} \\ & \mathrm{e}\end{array}$

(CV95:ColherPanela:70)

de bananeira

$$
\begin{gathered}
\left.\left(\mathrm{T}_{\mathrm{i}}\right)\right] \\
\mathrm{P}^{\mathrm{M}+1}
\end{gathered}
$$

um aspecto importante
(Ang97:EnsinoAngola:48)

Em construções de identificação, as duas unidades semânticas representam modos alternativos de visão da mesma entidade, não havendo, portanto, atribuição de propriedade, conforme exemplificam (32) e (33). Nesses casos, é também a palavra verbal (a cópula) que ocupa a posição medial obrigatória, a unidade semântica não tópica a ela se pospõe e o sintagma Tópico assume a posição $\mathrm{P}^{\mathrm{I}}$. 
(32)

$$
\begin{array}{cccc}
{\left[\left(\mathrm{R}_{\mathrm{i}}\right)_{\mathrm{TOP}}\right.} & & \left.\left(\mathrm{R}_{\mathrm{H}}\right)\right] & \\
\mathrm{P}^{\mathrm{I}} & \mathrm{P}^{\mathrm{M}} & \mathrm{P}^{\mathrm{M}+1} & \\
\text { o direito } & \text { é } & \text { o instrumento } & \text { (Bras87: EconomiaSociedade) } \\
& & \text { do estado } &
\end{array}
$$

$$
\begin{aligned}
& {\left[\left(\mathrm{R}_{\mathrm{i}}\right)_{\text {TOP }}\right.} \\
& \mathrm{P}^{\mathrm{I}} \quad \mathrm{P}^{\mathrm{M}} \quad \mathrm{P}^{\mathrm{M}+1} \\
& \text { a droga são os comprimidos (Ang97:Meninos de Rua:45) }
\end{aligned}
$$

A função Tópico pode ainda ser atribuída a Subatos Referenciais sem função de sujeito. É o que exemplifica (34), em que a função Tópico é aplicada ao sintagma nominal não sujeito mousse de barbear; em termos tradicionais essa oração tem o padrão OV, já que o sujeito não é expresso por nenhum sintagma nominal.

$$
\begin{aligned}
& {\left[\left(\mathrm{R}_{\mathrm{i}}\right)_{\mathrm{TOP}} \quad\left(\mathrm{T}_{\mathrm{i}}\right)\right]} \\
& \mathrm{P}^{\mathrm{I}} \quad \mathrm{P}^{\mathrm{M}} \\
& \text { mousses de barbear também, temos (PT96:BomSensoRosto05) }
\end{aligned}
$$

Caso interessante é (35), em que o Tópico é atribuído a um constituinte do sintagma nominal, caracterizando um caso de descontinuidade, a que Van de Velde (2012: 10) denomina Extração ${ }^{7}$. Para ele, o sintagma preposicionado em posição inicial serve como um modificador adverbial de limitação no nível da oração. O "fronteamento" deve-se à função tópica do Subato Referencial, mas o sintagma preposicional é morfossintaticamente integrado à oração e permanece no mesmo contorno entonacional do resto da oração.

$$
\begin{aligned}
& {\left[\left(\mathrm{R}_{\mathrm{i}}\right)_{\mathrm{TOP}}\right.} \\
& \mathrm{P}^{\mathrm{I}} \\
& \mathrm{P}^{\mathrm{M}} \quad \mathrm{P}^{\mathrm{M}+1} \\
& \text { daquele tronco grande cortavam um pedaço (PT94:AmassarCozer12) }
\end{aligned}
$$

7. Na tradição gramatical é denominada Anástrofe, uma figura de sintaxe. (cf. Cunha e Cintra 2008:641). 
Outro caso de descontinuidade ocasionada pela atribuição da função Tópico é ilustrado em (36). Aqui já não se trata de "fronteamento" de um sintagma preposicionado mas sim de um sintagma nominal. Observe que, sem a atribuição da função Tópico, ter-se-ia uma construção Tética.

$$
\begin{aligned}
& \begin{array}{cccc}
{\left[\left(\mathrm{R}_{\mathrm{i}}\right)_{\mathrm{TOP}}\right.} & & & (+\mathrm{id}+\mathrm{s})] \\
\mathrm{P}^{\mathrm{I}} & \mathrm{P}^{\mathrm{M}-1} & \mathrm{P}^{\mathrm{M}} & \mathrm{P}^{\mathrm{M}+1}
\end{array} \\
& \text { doutores sempre houve muito poucos (Ang97:EnsinoAngola:97) }
\end{aligned}
$$

Conforme propõem Hengeveld e Mackenzie (2008: 94), a função Tópico pode ainda ser atribuída a constituintes não configuracionais, ou seja, a Subatos que servem para indicar o cenário (setting) do estado-decoisas evocado, uma vez que o Componente Contextual contém também informações sobre as coordenadas espacial e temporal de ocorrência do estado-de-coisas. O cenário temporal, por exemplo, é dado a uma predicação de zero lugar, em (37), a uma predicação de um lugar, em (38), e a uma predicação de dois lugares, em (39), respectivamente pelos modificadores pouco tempo depois, antigamente e no primeiro dia.

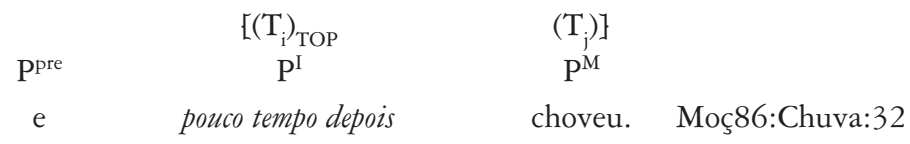

$$
\underset{\mathrm{P}^{\mathrm{I}}}{\left[\left(\mathrm{T}_{\mathrm{i}}\right)_{\mathrm{TOP}}\right.}
$$

antigamente

pouco tempo depois

$$
\text { choveu. Moç86:Chuva:32 }
$$

$$
\begin{gathered}
\text { (R)] } \\
\mathrm{P}^{\mathrm{M}+1}
\end{gathered}
$$

quitanda (Bra80:ViverComOutors:09)

$$
\begin{array}{ccc}
{\left[\left(\mathrm{T}_{\mathrm{i}}\right]_{\mathrm{TOP}}\right.} & \left(\mathrm{T}_{\mathrm{j}}\right) & \left.\left(\mathrm{R}_{\mathrm{i}}\right)\right] \\
\mathrm{P}^{\mathrm{I}} & \mathrm{P}^{\mathrm{M}} & \mathrm{P}^{\mathrm{M}+1}
\end{array}
$$

no primeiro dia

fizemos

uma visita,

(CV95:IlhaFogo:33)

Um exemplo da função Tópico atribuído a um Subato que indica o cenário espacial do estado-de-coisas evocado encontra-se em (40) e (41). Em (40), a atribuição da função Tópico ${ }^{8}$ torna uma predicação de Existência em uma construção categorial Tópico-orientada.

8. Esse tipo de Tópico tem sido denominado de sujeito psicológico (cf. Vidos, 1967, p. 378) 
(40)

$$
\begin{array}{ccc}
{\left[\left(\mathrm{R}_{\mathrm{i}}\right)_{\text {TOP }}\right.} & \left.\left(\mathrm{R}_{\mathrm{S}}\right)\right] \\
\mathrm{P}^{\mathrm{I}} & \mathrm{P}^{\mathrm{M}} & \mathrm{P}^{\mathrm{M}+1}
\end{array}
$$

nessepátio tem uma reserva de lenha (Bra80:Fazenda:18)

$$
\begin{array}{cccc} 
& {\left[\left(\mathrm{R}_{\mathrm{i}}\right)_{\mathrm{TOP}}\right.} & \left(\mathrm{T}_{\mathrm{i}}\right) & \left.\left(\mathrm{R}_{\mathrm{j}}\right)\right] \\
\text { Ppre } & \mathrm{P}^{\mathrm{I}} & \mathrm{P}^{\mathrm{M}} & \mathrm{P}^{\mathrm{M}+1} \\
\text { porque } & \text { cána Guiné } & \text { só existe } & \text { diferentes etnia. (GB95:SIDA:15) }
\end{array}
$$

Em português, é possível também a atribuição da função Tópico a Subatos que fornecem um tipo específico de orientação para o estoque de informação nova a ser apresentada (cf. Hannay e Martínez-Caro 2008:60). Entre esse tipo encontram-se os modificadores que indicam o Modo do estado-de-coisas, como (42), em que o sintagma preposicionado com a costura restringe todo o estado-de-coisas "possibilidade de sobrevivência em toda parte".

$$
\begin{aligned}
& \begin{array}{ccc}
{\left[\left(\mathrm{R}_{\mathrm{i}}\right)_{\text {TOP }}\right.} & \left(\mathrm{T}_{\mathrm{i}}\right) & \left.\left(\mathrm{R}_{\mathrm{j}}\right)\right] \\
\mathrm{P}^{\mathrm{I}} & \mathrm{P}^{\mathrm{M}} & \mathrm{P}^{\mathrm{M}+1}
\end{array} \\
& \text { com a costura consegue-se em toda parte (To-Pr96:Costureira:22) } \\
& \text { sobreviver }
\end{aligned}
$$

O português caracteriza-se ainda por permitir, com muita facilidade, a ocorrência de Tópicos Múltiplos, conforme propõem Hengeveld e Mackenzie (2008:94). Dessa forma, são possíveis construções que indicam tanto o cenário do estado-de-coisas evocado quanto o indivíduo sobre o qual se constrói o comentário. É o que mostram as ocorrências (43) e (44). Em (43), você indica a entidade sobre a qual se constrói o comentário, e todas as noites apresenta o cenário de frequência de ocorrência do estado-de-coisas; já em (44) o cenário temporal é dado pelo advérbio boje e a entidade individual, pelo sintagma nominal o bomem.

$$
\begin{array}{cccccc}
{\left[\left(\mathrm{R}_{\mathrm{i}}\right)_{\mathrm{TOP}}\right.} & \left(\mathrm{R}_{\mathrm{j}}\right)_{\mathrm{TOP}} & \left(\mathrm{T}_{\mathrm{i}}\right) & \left(\mathrm{R}_{\mathrm{k}}\right) & \left.\mathrm{T}_{\mathrm{j}}\right] & \\
\mathrm{P}^{\mathrm{I}} & \mathrm{P}^{\mathrm{I}+1} & \mathrm{P}^{\mathrm{M}} & \mathrm{P}^{\mathrm{M}+1} & \mathrm{P}^{\mathrm{F}} & \\
\text { vocês } & \text { todas as noites } & \text { tinham } & \begin{array}{c}
\text { esse tra- } \\
\text { até mais ou }
\end{array} & \text { (Ang97:Meninos de } \\
& & & \text { balho } & \text { menos ao } & \text { Rua:18) } \\
& & & & \text { amanhecer? }
\end{array}
$$


(44)

$$
\begin{aligned}
& \begin{array}{cccc}
{\left[\mathrm{R}_{\mathrm{i}}\right)_{\mathrm{TOP}}} & \left(\mathrm{R}_{\mathrm{i}}\right)_{\mathrm{TOP}} & & \left.\left(\mathrm{T}_{\mathrm{i}}\right)\right] \\
\mathrm{P}^{\mathrm{I}} & \mathrm{P}^{\mathrm{I}+1} & \mathrm{P}^{\mathrm{M}} & \mathrm{P}^{\mathrm{M}+1}
\end{array} \\
& \text { boje obomem está muito mais (PT96:BomSensoRosto:78) } \\
& \text { aberto }
\end{aligned}
$$

A atribuição de Tópico, em português, não se restringe a Subatos Referenciais. Hengeveld e Mackenzie (2008:95) observam que Subatos Atributivos podem também ser o ponto de partida da asserção, como mostra a ocorrência (45), enunciada num contexto de pergunta sobre a participação da informante numa escola de samba; (46), cuja pergunta se refere à periculosidade do javali; e (47), à pergunta como é que é apascentar o gado? Note que em (47), no Nível Representacional, o Subato Atributivo corresponde a um estado-de-coisas.

$$
\begin{array}{ccccc}
{\left[\left(\mathrm{T}_{\mathrm{i}}\right)_{\text {TOP }}\right.} & \left(\mathrm{R}_{\mathrm{i}}\right)_{\text {TOP }} & & \left.\left(\mathrm{T}_{\mathrm{i}}\right)\right] & \\
\mathrm{P}^{\mathrm{I}} & \mathrm{P}^{\mathrm{I}+1} & \mathrm{P}^{\mathrm{M}-1} & \mathrm{P}^{\mathrm{M}+1} & \\
\text { desfilar } & \text { nós } & \text { nunca } & \text { desfilamos } & \text { (Bra80:Samba:71) }
\end{array}
$$

$\begin{array}{ccccc}{\left[\left(\mathrm{T}_{\mathrm{i}}\right)_{\text {TOP }}\right.} & & & \left.\left(\mathrm{R}_{\mathrm{i}}\right)\right] & \\ \mathrm{P}^{\mathrm{I}+1} & \mathrm{P}^{\mathrm{M}} & \mathrm{P}^{\mathrm{M}+1} & \\ \text { perigosos } & \text { somos } & \text { nós } & \text { (PT97:BoaPontaria:105) } \\ & & & & \\ \sum \mathrm{A} & {\left[\left(\mathrm{T}_{\mathrm{i}}\right)_{\mathrm{TOP}}\right.} & & \left.\left(\mathrm{T}_{\mathrm{i}}\right)\right] & \\ \mathrm{P}^{\mathrm{I}} & \mathrm{P}^{\mathrm{I}+1} & \mathrm{P}^{\mathrm{M}} & \mathrm{P}^{\mathrm{M}+1} & \\ \text { ortanto } & \text { apascentar } & \text { é } & \text { mais ou } & \text { (Moç86:MeniniceMachamba:30) } \\ & \text { gado } & & \text { menos isso }\end{array}$

O padrão de ordenação para construção Categorial Tópico-orientada é representado em (48):

(48) NI: $\quad\left[(\mathrm{SA})_{\text {TOP }}(\mathrm{SA})^{\mathrm{N}}\right]$

NM: $\quad \mathrm{P}^{\mathrm{I}} \mathrm{P}^{\mathrm{ION}} \quad \mathrm{P}^{\mathrm{M}} \mathrm{P}^{\mathrm{M}+\mathrm{N}}$

Como evidenciam os dados analisados, a função Tópico, em portuuguês, caracteriza-se por poder ser atribuída (i) a Subatos Referenciais; (ii) a Subatos Atributivos; e (iii) a mais de um Subato concomitantemente, todos eles marcados pela posição no início da oração. 
O Subato Referencial Tópico pode ser:

a) um constituinte configuracional que, no Nível Morfossintático, desempenha a função de sujeito;

b) um constituinte configuracional não-sujeito, tanto pertencente à oração quanto ao sintagma (casos de descontinuidade);

c) um constituinte não configuracional, que indica o cenário (setting) do estado-de-coisas evocado, ou que fornece um tipo específico de orientação para o estoque de informação nova a ser apresentada;

Essas várias possibilidades de atribuição da função Tópico demonstram ser o português uma língua muito sensível a essa função pragmática, o que, nos termos de Li e Thompson (1976), caracteriza uma língua com proeminência de Tópico.

\section{CONSIDERAÇÕES FINAIS}

Esses resultados indicam que Moldes de Conteúdo Configuracional Tópicoorientado apresentam uma entidade que fornece orientação para o estoque de informação nova a ser apresentada, ou seja, um Tópico; contribuem, dessa forma, para o avanço do discurso, fazendo parte, portanto, da porção figura, nos termos de Hopper e Thompson (1980). Isso vai se refletir na linearização dos constituintes, que ocorre no Nível Morfossintático: o constituinte Tópico assume a posição $\mathrm{P}^{\mathrm{I}}$ ou uma de suas relativas $\left(\mathrm{P}^{\mathrm{I}+\mathrm{n}}\right)$, o sintagma verbal $(\mathrm{Vp})$ aloca-se em $\mathrm{P}^{\mathrm{M}}$, e os outros constituintes configuracionais colocam-se nas posições relativas à direita e à esquerda de $\mathrm{P}^{\mathrm{M}}$, configurando o padrão em (49):

\begin{tabular}{|l|c|c|c|c|c|}
\hline (49) & $\mathbf{P}^{\mathrm{I}}$ & $\mathbf{P}^{\mathrm{M}-1}$ & $\mathrm{P}^{\mathrm{M}}$ & $\mathbf{P}^{\mathrm{M}+1}$ & $\mathbf{P}^{\mathrm{F}}$ \\
\cline { 2 - 6 } & Tópico & $\begin{array}{c}\text { operador } \\
\text { configuracional }\end{array}$ & $\mathrm{Vp}$ & $\begin{array}{c}\text { constituinte } \\
\text { configuracional }\end{array}$ & $\begin{array}{c}\text { constituintes não- } \\
\text { configuracionais }\end{array}$ \\
\hline
\end{tabular}

Moldes de Conteúdo Tético e Apresentativo, por outro lado, não apresentam um Tópico, mas têm papéis bem definidos no desenvolvimento do discurso, ou seja, propiciam ao falante sustentar, ampliar ou comentar a linha principal do discurso, servindo de pano de fundo, já que, no caso das 
téticas, contribuem para a descrição ou montagem do cenário no avanço do discurso, e, no caso das apresentativas, introduzem um novo referente, que fornecerá material de suporte para continuação do discurso. Isso também é refletido na linearização dos constituintes, no Nível Morfossintático.

Assim, por não disporem de Tópico, construções Téticas apresentam o padrão de ordenação representado em (50); já as construções Apresentativas exibem o padrão em (51):

\begin{tabular}{|c|c|c|c|}
\hline (50) & $\mathrm{P}^{\mathrm{F}-2}$ & $\mathrm{P}^{\mathrm{F}-1}$ & $\mathrm{P}^{\mathrm{F}}$ \\
\cline { 2 - 4 } & $\begin{array}{c}\text { operador configuracional } \\
\text { Foco }\end{array}$ & $\begin{array}{c}\mathrm{V}_{\mathrm{p}} \\
\text { Foco }\end{array}$ & constituinte configuracional Foco \\
\hline
\end{tabular}

\begin{tabular}{|c|c|c|c|}
\hline \multirow{2}{*}{$51)$} & $\mathrm{P}^{\mathrm{M}-1}$ & $\mathrm{P}^{\mathrm{M}}$ & $\mathrm{P}^{\mathrm{F}}$ \\
\cline { 2 - 4 } & operador configuracional & $\mathrm{Vp}$ & constituinte configuracional Foco \\
\hline
\end{tabular}

Como é possível notar, as estruturas oracionais do português refletem decisões assumidas na formulação do Nível Interpessoal, que vão se refletir na ordenação dos constituintes no Nível Morfossintático. Em outras palavras, a ordenação de constituintes é uma forma de expressar linguisticamente as ações assumidas pelos falantes a fim de conseguir seus propósitos comunicativos.

Além disso, a análise mostra que dizer que o português é uma língua SVO não se justifica, uma vez que nem todo sujeito se antepõe ao verbo; isso só acontece se o sujeito for Tópico. Nesse sentido, é mais coerente dizer que o português é uma língua Categorial Tópico-orientada.

Recebido em maio de 2012 Aprovado em agosto de 2012 E-mail: pezatti@ibilce.unesp.br

\section{REFERÊNCIAS BIBLIOGRÁFICAS}

Azeredo, José Carlos de. 2008. Gramática Houaiss da Lingua Portuguesa. São Paulo: Publifolha.

Barbosa, Jerônimo Soares. 1881. Gramática philosophica da língua portuguesa. Lisboa: Academia Real das Ciências. 
Bentivoglio, Paola \& Maria Luíza Braga. 1988. Espanhol, Português e ordem de palavras. D.E.L.T.A. 4/2: 163-82.

Berlinck, Rosana de Andrade. 1989. A construção V+SN no português do Brasil: uma visão diacrônica do fenômeno da ordem. In: Fernando Tarallo Org. Fotografias sociolingüústicas. Campinas: Pontes.

Berman, Ruth. 1980. The case of an (S)VO language: subjectless constructions in modern hebrew. Language 56/4: 759-75.

Braga, Maria Luíza. 1984. Tópico e ordem vocabular. Abralin 6: 174-88.

Braga, Maria Luíza. 1986. Construções de tópico de discurso. Relatório final do projeto subsídios sociolingüísticos do projeto censo à educação (FINEP). Rio de Janeiro.

Braga, Maria Luíza. 2009. Construções clivadas no português do Brasil sob uma abordagem funcionalista, Matraga 16: 173-196.

Callou, Dinah et al. 2002. Topicalização e deslocamento à esquerda. In: Ataliba Teixeira de Castilho (org). Gramática do Português Falado. v. 3: As abordagens. Campinas, SP: Editora de UNICAMP, São Paulo: FAPESP.

Camacho, Roberto Gomes \& Erotilde Goreti Pezatti. 1997. Aspectos funcionais da ordem de constituintes. D.E.L.T.A . 13/2:191-214.

Castilho, Ataliba Teixeira de. 2010. Nova Gramática do Português Brasileiro. São Paulo: Contexto.

Cunha, Celso \& Lindley Cintra. 2008. Nova gramática do Português Contemporâneo. $5^{\text {a }}$. ed. Rio de Janeiro: Lexikon.

Decat, Maria Beatriz. 1989. Construções de Tópicos em Português: uma abordagem diacrônica à luz do encaixamento no sistema pronominal: In: Fernando Tarallo Org. Fotografias Sociolingüisticas. Campinas: Pontes.

Dik, Simon. 1981. The interaction of subject and Topic in Portuguese. In: Machtelt Bolkestein et al. Orgs. Predication and Expression in Functional Grammar. New York: Academic Press.

Dik, Simon. 1989. The theory of functional grammar. Part I. The structure of the clause. Dordrecht: Foris.

Dik, Simon. 1997a. The Theory of Functional Grammar. Pt 1: The structure of the clause. (Ed. Kees Hengeveld). Berlin/New York: Mouton de Gruyter.

Dryer, Matthew. 1991. SVO languages and the OV:VO typology. J. Linguistics 27: 443-82. 
DuARTE, Inês. 2003. Relações gramaticais, esquemas relacionais e ordem de palavras. In: Maria Helena Mira Mateus et al. Gramática da língua portuguesa. Lisboa: Editorial Caminho.

FERrARI, Lilian. 1990. Distribution and function of word order variation in brazilian portuguese. Journal of Pragmatics 14: 649-66.

Greenberg, Joseph. 1963. Some universals of grammar with particular reference to the order of meaningful elements. In: . Ed. Universals of language. Cambrige, Massachusetts: MIT Press.

Garcia, Othon. 1982. Comunicação em prosa moderna. Rio de Janeiro: Editora da Fundação Getúlio Vargas.

Givón, Talmy. 1976. Topic, Pronoum and Grammatical Agreement. In: Charles Li. Ed. Subject and Topic. New York: Academic Press.

Hannay, Mike \& Elena Martínez Caro. 2008. Last things first: a FDG approach to clause-final focus constituents in Spanish and English. In: Maria de los Angeles Gómez-González, John Lachlan Mackenzie e Elsa González Álvarez (eds). Languages and Cultures in Contrast and Comparison. [Pragmatics and Beyond New series 175] Amsterdam \& Philadelphia: John Benjamins: 33-68.

Hengeveld, Kees \& John Lachlan Mackenzie. 2008. Functional Discourse Grammar. Oxford: Oxford University Press.

Hopper, Paul \& Sandra Thompson. 1980. Transitivity in grammar and discourse. Language 56/2: 251-99.

Kato, Mary et al. (2002). Preenchimento em fronteiras de constituintes. In: Rodolfo Ilari (org.) Gramática do português falado. Vol. 3: As abordagens. Campinas: Editora da UNICAMP.

Lehmann, Winfred P. 1978. (ed.). Syntactic Typology. Sussex: The Harvester Press, 1978.

LI, Charles \& Sandra Thompson, A. 1976. Subject and Topic: a new typology of Language. In: Charles Li. Org. Subject and Topic. New York: Academic Press.

LirA, Solange de Azambuja. 1986. Subject postposition in Portuguese. DELTA 2/1: 17-36.

Lopes, Doraci Kalvon. 1981. O papel da inversão sujeito-predicado na percepção de sentenças. Estudos Linguísticos 4: 71-89.

Mateus, Maria Helena Mira et al. 1983. Gramática da língua portuguesa. Coimbra: Almedina.

Mateus, Maria Helena Mira et al. 2003. Gramática da língua portuguesa. Lisboa: Editorial Caminho. 
PáduA, Maria da Piedade Canaes e Mariz de. 1960. A ordem de palavras no português arcaico. Coimbra, Instituto de Estudos Românicos.

PezAtTi, Erotilde Goreti. 1992. A ordem de palavras em português, aspectos tipológicos e funcionais, Tese de Doutorado, Universidade Estadual Paulista, Araraquara. Inédita.

Pezatti, Erotilde Goreti \& Roberto Gomes Camacho. 1997. Aspectos funcionais da ordem de constituintes. DELTA13/2: 191-214.

Pontes, Eunice. 1982. A ordem VS em português. Ensaios de linguística Cadernos de linguística e teoria literária 7: 90-137.

Pullum, Geofrey. 1977. Word order universal and Grammatical relations. In: Peter Cole \& Jerrold Sadock. Ed. v. 8. Syntax and Semantics. New York: Academic Press.

Tarallo, Fernando. 2002. Preenchimentos em fronteiras de constituintes II: uma questão de variação interna, externa, ou um caso de variação individual? In: Ataliba Teixeira de Castilho. Org. Gramática do Português Falado. v. 3: As Abordagens. Campinas, SP: Editora de UNICAMP, São Paulo: FAPESP.

TARAllo, Fernando. et al. 2002. Rupturas na ordem de adjacência canônica no português falado. In: Ataliba Teixeira de Castilho. Org. Gramática do Português Falado. v. 1: A Ordem. Campinas, SP: Editora de UNICAMP, São Paulo: FAPESP.

Urbano, Hudnilson. 1987. A Ordem do sujeito no português falado. Estudos Linguísticos 14: 41-56.

VIDos, Benedek Elemér. 1967. Manual de lingüística românica. Madrid: Aguillar.

Votre, Sebastião \& Antony Naro. 1986. Emergência da sintaxe como efeito discursivo. Relatório final de subsídios sociolingüisticos do projeto censo à educação (FINEP). Rio de Janeiro. 